\title{
Desarrollo de una aplicación de predicción de vida a fatiga por daño acumulativo aplicado a semirremolques de tres ejes
}

\author{
L. Tello Carbonel, L. Castejón Herrer \\ Nuevas Tecnologías en Vehículos y Seguridad Vial (VEHI-VIAL) Instituto de Investigación en Ingeniería \\ de Aragón (I3A). Universidad de Zaragoza, Mariano Esquillor s/n, 50018, Zaragoza, España. \\ Tel. +34-976761888, e-mail: \{ltello, luiscast\}@unizar.es
}

\begin{abstract}
El transporte por carretera supone un alto porcentaje sobre el total del transporte de mercancías. Esto hace necesario que los vehículos estén optimizados tanto en diseño como en peso. El uso de aceros de alta resistencia combinados con aceros convencionales ha hecho posible reducciones de peso significativas sobre la estructura del vehículo. Estas nuevas configuraciones aligeradas están construidas usando espesores muy bajos, lo que suele degenerar en la aparición de fallos prematuros por fatiga. Además, durante los procesos de soldadura, se producen cambios en las propiedades de los materiales en las zonas próximas al cordón, por lo que es necesario conocer dichos cambios para poder realizar las predicciones de vida de la estructura correctamente. Para poder predecir la vida de los semirremolques, en la Universidad de Zaragoza, se desarrolló una subrutina de predicción de vida a fatiga para semirremolques de tres ejes basándose en la maniobra más crítica que realizan este tipo de vehículos, la maniobra de giro de radio mínimo. Esta subrutina aunque es una primera aproximación del cálculo de la vida de un semirremolque, no tiene en cuenta los efectos del daño acumulativo que puedan deberse al resto de maniobras realizadas por un vehículo de estas características. El modelo de subrutina, que se esta investigando y se pretende desarrollar, se basa en el daño acumulativo por fatiga según la diferenciación en el uso que se va a hacer de cada semirremolque y de las diferentes cargas a las que estarás sometidos los vehículos en cada caso.
\end{abstract}

